\title{
The Quality Of Work Life And Job Stress Among Librarians In Public Tertiary Institutions.
}

Adegboye Moyosore

A post-graduate student of Library and Information Studies, Federal University of Agriculture, Abeokuta, Ogun State, Nigeria

adegboyemoyo@gmail.com

\begin{abstract}
The issues regarding the quality of work life and job stress is a global phenomenon which cuts across diverse changing and work environment. The success of any organization depends largely on the strategies adopted to improve the quality of work life of employees especially that of the librarians. The overall focus of the paper is to analyze the nature of work life and employment stress among librarians in public tertiary institutions. It is meant to determine the effect of job stress on the effectiveness of librarian's performance in public tertiary institutions. It examines the causes of job stress among librarians in public tertiary institutions. It evaluated theories related to various components of quality work life and job stress. The research design used for the study was descriptive form of research and the study tested the hypotheses with relevant statistical instruments. The results showed that most librarians experienced high job stress resulting in unsatisfactory quality work life. It revealed the effects and impact of stress on librarians and their over-all performance. Job stress on librarians results in ill-health and loss of man hour which further manifests in low productivity. It is therefore necessary to ensure that stress is reduced to the barest minimum in the library workplace. Creating a healthy working environment is paramount in this regard. The provision of adequate facilities is also important since it helps librarians to perform optimally. Both the male and female library staff need to strike a balance between their job and family. Those who have children must as a matter of fact ensure that they employ adult house help to manage their home activities and take good care of their children while at work. It is indeed difficult to manage the work and home fronts without putting adequate plans in place. The population was obtained from various public tertiary institutions in Ogun state. Data analysis was done through descriptive statistics where measures of central tendencies and dispersion include frequency counts, means and percentages. The data was further analysed with the ANAVO with the help of the statistical package ver23
\end{abstract}

Published by IJRP.ORG. Selection and/or peer-review under responsibility of International Journal of Research Publications (IJRP.ORG)

Keywords: Quality of work life: job stress: librarians

\subsection{Introduction}

Stress has become part of our lives and every last one of us responds to pressure in an unexpected way. Stress produces physical, hormonal, and manufactured changes in the body to animate the working of the heart, lungs, and muscles (Gazzaniga and Heatherton, 2003). Work pressure will be pressure inborn in work and can happen 
when an irregularity exists between the solicitations of the workplace and a person's ability to execute these solicitations (Henry and Evans, 2008). Custodians in scholastic libraries are not excluded from pressure. They complete the obligations of securing, preparing and safeguarding library materials for openness to staff, understudies, and specialists. ILO (2009) as referred to by Ogunsola (2004) believed that college libraries as the core of the organizations which are required to keep up standard books, diaries and general media assortments. Custodians should subsequently guarantee accessibility of assets and productive administrations which thusly carries fulfilment to the customers. The development of ICT in college libraries has gotten a turnaround the heretofore manual exercises of the bookkeepers. Aside from utilizing different of ICT offices to ease, procure and measure materials, the custodian draws in same in other expert tasks, for example, ordering and abstracting, spread of data, current mindfulness administrations and client schooling. These exercises no uncertainty place high requests on administrators, in this manner bringing about pressure. Bamber (2011) sees that extreme occupation requests can bring about over the top pressure.

Stressors from work can lead the body to encounter some physiological response which can influence an individual truly and intellectually. Components that make and breeds work environment stress are far reaching and reach from mechanical change and worldwide serious pressing factors to poisonous workplaces and administrative harassing (Colligan and Higgins, 2006). (Colligan and Higgins, 2006) further affirms that cutting back, quick changes in serious pressing factors, innovation, and work methods, expanded degrees of occupation uncertainty, and truly requesting clients make the present work environment seemingly considerably more pressure loaded than it was only 10 years prior. Likewise, absence of self-sufficiency, troublesome or stressed cooperation with partner laborers just as the executives, attacks from bosses and practically zero open doors for progression in one's aptitude level add to making the present workplace more distressing than in earlier years. Lazarus and Folkman (1984) keep up that pressure is the resultant outcome of individuals' convictions that they are inadequate in required assets to face testing occasions. It bodes well that psychological capital is one expected resource for help delegates with confronting testing and disturbing events at the work environment which accordingly may direct the negative results of work weight on laborer's quality work life. Numerous researchers have assessed that most utilized administrators that an extraordinary extent of their every day life is spent grinding away. A compensating position gives rest of cerebrum while a powerless occupation prompts nonattendance of concordance which may finally incite pressure. Akinboye, Akinboye and Adeyemo (2002) alluding to the 1992 Annual United Nations Report portray work pressure as a 20th century sickness and moreover found in an audit report that essentially $80 \%$ of delegates depict their work as troubling. Individuals go through various types of pressure exuding from the workplace just as the conditions under which they work. Aldwin (2007) likewise asserts that stressors can be in type of remaining task at hand, speed of work, risky or poisonous working conditions, inadequately planned climate, social conflict with managers, partners, and isolation reliant on age, sex and disappointment related to the social relationship of the workplace. Administrators can possibly conquer pressure when they perceive that it is more valuable to oversee it than to encounter its belongings. Roy (2005) keeps up that attention to all the parts of pressure, knowledge of the circumstances that produce pressure are on the whole significant strides during the time spent pressure the executives and the personal satisfaction after work is the most difficulties the administrators are being confronted with. At the point when we distinguish the presence and impacts of weight on our lives, we ought to have the option to deal with its source decidedly or as curators change our discernment towards it, (Routray and Satpathy, 2007). The unfavourable impacts of weight on bookkeepers, clients just as the parent organizations request that techniques be set up towards its administration. Bamber (2011) gave recommendations on how laborers can beat word related pressure. These recommendations incorporate making a difficult rundown, organizing one's issues, defining objectives, setting up standards of accomplishment, arranging intercessions, creating self-improvement treatment plan, checking and auditing progress in an examination Scheneider (1991) completed an exploration on pressure and employment fulfilment; a correlation between individuals working in open libraries with specialized administrations staff in huge public library framework. The investigation uncovered that the significant reasons for pressure to the representatives 
considered incorporate work over-burden, helpless assets accessibility and helpless workplace. The obstruction of the home front with workplace requests in some cases comprises pressure to administrators particularly where the staff concerned can't oversee both adequately. Library stress offers ascend to in chronic weakness conditions, low work yield, expanded heartbeat and dread, helpless administrations to clients bringing about client dissatisfaction. Aldwin (2001) asserted that pressure offers ascend to reactions, for example, quick pulses, more noteworthy sharpness and the limit with regards to eruptions of energy. Quality Work Life is conceptualized as far as need fulfilment. Laborers carry a group of their necessities to the association and are probably going to appreciate a feeling of Quality Work Life to the degree that these requirements are fulfilled through their participation in the association. Quality Work Life is conceptualized as beginning from a participation of individual and legitimate segments. Its own fundamental establishments are discovered basically in the psychological necessities of the workers. Its various leveled establishes are arranged in the definitive mission, reward structures, general working environment, work plan and business development plans. Mirvis and Lawler (1984), suggested that Quality work life was connected with satisfaction with wages, hours and working conditions, depicting the fundamental segments of a good sort of work life as; safe working environment, impartial wages, comparable business openings and open entryways for progress. The nature of connections that representatives have at work has reliably connected to work pressure and has passionately influenced their way of life of family relationship (Payne, 1980). This can be valid for librarianship and data calling. These difficulties have been perceived to be of three kinds: relationship with associates/work gatherings; relationship with directors/pioneers; and relationship with customers/clients. In every one of these connections the association assume a significant part particularly in reinforcing these relationship for example by making an air of trust between the administration and laborers, among specialist and laborers, settling fractures, advising, human connection preparing, and social help administrations.

\subsection{Statement of the problem}

Studies on job stress and quality of work life have been carried out in many workplaces around the world like hospitals, colleges, factories, companies etc. Only a few of such studies have been reported in library workplaces. Most public tertiary libraries are usually open to staff and students. Knowing full well that tertiary institutions in Nigeria are highly populated. It results in the job of administrators and personnel being more tasking and cumbersome. Administrators often experience pressure in college libraries because of high client population especially during examination periods. Unmanaged stress often results in breakdown and chronic weakness of body system. This usually brings about decreased work productivity resulting in client dissatisfaction. Be that as it may, most libraries require more work-hours given the quantum of work and the huge number of clients. The status of most libraries puts a lot of pressure on their administrators. It is realized that incessant changes in workplace straightforwardly and in a roundabout way impact the presentation and efficiency of an administrator and thusly the association needs to have successful adapting systems set up to deal with the eventual outcomes of execution under pressure. Workers perform better when treated in a positive way than being worried with loads of occupations. Stress can cause mental and actual breakdown among administrators and the nature of their work life of as a representative. Both public and private area administrators have confronted a few difficulties in the new past. For a long time many examination work have been done on occupation fulfillment and all the more as of late interest has emerged into the more extensive ideas of stress and quality work life, the exact idea of the connection between these ideas are as yet being investigated. Stress at work is regularly thought to be in disengagement, wherein it is evaluated dependent on consideration regarding a person's pressure the executives abilities or the wellsprings of stress will demonstrate to give a sufficient premise to powerful mediation. This examination looks to address how best workplace can diminish pressure and improve nature of work life for bookkeepers in open tertiary establishments. 


\subsection{Research Questions}

i. What is the level of job stress among librarians in public tertiary institutions

ii. What is the effect of job stress on effectiveness of librarians performance in public tertiary institutions

iii. What are the causes of job stress among librarians in public tertiary institutions

\subsection{Research Hypotheses}

i. There is significant effect of job stress among librarians in public tertiary institutions

ii. There is significant effect of job stress on effectiveness of librarians' performance in public tertiary institutions

iii. Job stress has significant effect on librarians in public tertiary institutions

\subsection{Literature Review}

Wikipedia (2007) classify pressure utilizing various standards, yet for the most part pressure was gathered as physical or mental. This was furthermore explained that the genuine pressing factor is the one that bother or brings expeditious or long stretch negative effect on your physical or genuine prosperity. This may not actually impact your psychological (or mental) state. While the psychological pressing factor brings brisk or long stretch unsettling influence or negative effect on your psychological or mental state. This may not actually have any brief effect on your genuine state. In any case, these two social events can be amazingly natural for instance your real state can impact your psychological state and the reverse way around. Lehnert (2002) in like manner his statement mastermind pressure as exceptional (brief) which can be one-time scene that for the most part goes to and fro quickly. Its effect he portrayed can last from minutes or hours to days or weeks. While the industrious (long stretch) which can be achieved by a keeping line of upsetting recurrence of a persistent condition. Ferkol (1998) reported the examination of Schneider in 1991 on pressing factor and occupation satisfaction by differentiating people working without trying to hide organizations and those working in specific organizations in colossal public library structure. The examination was coordinated considering the creating stresses of the delegates working at the library; there were no enough agents to manage the leftover weight and it gave the possibility that this was hurtfully influencing the workers' prosperity (Schneider 1991). The discoveries from the examination uncovered that separated from the excessive amount of heap of work influencing the soundness of laborers, there were more factors welcoming more prominent weight on the specialists like helpless financing which prompts helpless accessibility of assets, the board's helpless correspondence with laborers, inability to permit laborers to take an interest in dynamic and helpless workplace. Burge (1987) gives the result from his pressing factor the board workshops using pack meeting to accumulate data from people checking out the workshop from different sorts of libraries, similarly as people holding different circumstances in the libraries. His revelations uncovered that different social affairs of caretakers oftentimes had similar slants concerning work satisfaction and stress. He went further to uncover that cataloguers for example conveyed that they didn't get affirmation for their undertakings, yet rather got complaints regarding subject headings that were not significant, and that dealing with was not done quickly enough. Routray and Satpathy (2007) depicted the sorts of pressure in electronic library atmosphere and broadly isolated them into: Technological, Physical, Mental and Situational. Creative pressing factor was depicted as the pressing factor on account of the unforeseen development and utilization of information propels among the library and information specialists. Due to speedy change in PC hardware and programming, oldness of existing gear and writing computer programs is a normal marvel in basically all libraries. Consequently there is the need to keep awake with the changing advances which due to financial, time or inventive objectives, it is difficult to 
do. Lowe (2000) conveyed the concern that sum may have gotten critical since the $1990^{\text {es }}$ s and that the interruption with it may stun chiefs and procedure makers to concealed issue which should be tended to by looking farther than benefit. He there contemplated that first class work can't avoid being work that is respectable, critical, life redesigning, and expert centered. It in any case actually offers befits to supervisors and public monetary prospering. Quality work life impacts the idea of work in families and organizations similarly as the monetary centrality of the country. Goodale, passage, burke and Jonyer (1975), drove interviews in which they asked the respondent how they would portray the articulation quality work life, the most as regularly as conceivable referred to parts describing quality wok life were mental success, the work environment recognizing or pursuing one point for the duration of regular daily existence and the social atmosphere gave by others. It is additionally seen that actual pressure was depicted as the negative impact of actual effort on the actual soundness of library laborers at work. For instance, the computerized library climate has changed the actual design of the work climate. Due to sitting before PC for a long hour, working in a cooled atmosphere, etc, have achieved the real pressing factor and affliction. This is on numerous occasions set off by exhaust, nonappearance of rest and horrendous eating schedule. Mental pressing factor is followed to a people's mental point of view, which incorporates suspicion, fears, regrets, etc Situational stress is explained as gotten from the relationship with the outer world like. For example, pressure turns out to be important for a library boss pressure as a result of another position or developing position. It may in like manner be pressure in light of association with colleagues, bosses or sponsors. This is maintained by the examination of Haack, Jones and Roose (1984) and therefore suggested planning in correspondence and stress the board as answers for this issue. Nawe (1995) also explained that work hardship can cause pressure since library and information specialists have various bosses who differ on what the agent should do. In spite of the fact that pressure is also achieved by work dubiousness which is accessible when a laborer doesn't understand that for which the person being referred to is proficient. She explained also that when delegates don't use their capacities, it might be as horrendous as being depleted however accountants may experience pressure in aiding advocates since they don't have the chance to transform into an expert on each and every structure. At the point when an individual isn't happy with his life at work that is needs Quality Work Life a few side effects/markers can be seen. They may be classified as:

Physiological markers - these are pointers that show up as actual signs on an individual's prosperity on account of low quality Work Life. The transitory pointers can be shortcoming, headaches and affliction which can develop into long stretch markers like coronary ailment, hypertension, stomach ulcers among others.

Mental markers - these are antagonistic pointers in an individual's perspectives or feelings. They may incorporate nervousness, disposition swings, and general disappointment with everything at work, low or no reaction to inspiration.

Conduct pointers - these are changes in a person's typical conduct that show low quality Work Life. They incorporate expanded truancy, expanded hostility and crabbiness, taking longer on undertakings, deteriorated vocations. Lau, wong, chan and Law (2001), operationalised Quality Work Life as the ideal work environment that supports and advances satisfaction by outfitting agents with compensations, proficient steadiness and livelihood improvement openings. In a roundabout way the definition demonstrates that a person who isn't fulfilled won't be profitable subsequently the association ought to endeavor to furnish the workers with employer stability and vocation development opportunity for their own just as expert development. Mullins (2005), to interpret the idea of Quality Work Life into training, it is best perceived on the off chance that it is viewed as an objective, a cycle of accomplishing that objective and as a way of thinking setting out the manner in which individuals ought to be overseen.

As an objective - this is improving authoritative adequacy through the production of additionally testing, fulfilling, and compelling positions and workplace.

As a way of thinking - this is seeing individuals as resources fit for contributing abilities, information, experience, and responsibility, as opposed to „,costs" that are just augmentations of the creation cycle. It battles that engaging affiliation and giving the atmosphere wherein, it can flourish, produces generous prizes for the 
two individuals and the affiliation. Serey (2006), battled that Quality of Work Life is identified with significant and fulfilling work it incorporates the chance to practice ones gifts and abilities to confront difficulties and circumstances that require free activity and self-bearing. Furthermore, an action thought advantageous with the individual included ought to be considered during the time spent planning tasks to advance accomplishment of individual and authoritative objectives. Stress is a mind boggling human issue that has drawn in the consideration and investigation of individuals from the beginning of history. All through history, therapists, ministers, specialists, customary and conventional clinical professionals, government assistance authorities, armed force administrators and numerous others who have interest in human issues have centered their examination regard for what stress includes and how to manage it. It is fascinating to see that proof of pressure is inescapable among military work force, bank chiefs, educators, dealers, carriers, government authorities and understudies. Understudies' pressure, for example, increments at the time of experiencing the afflictions of task work with class work, or the dread of joining the long line of the un-utilized toward the finish of their different courses of control. Arikewuyo (2004) considers pressure as any effect which disturbs the trademark agreement of the body which consolidates genuine injury, difficulty and such a sicknesses and enthusiastic aggravations. Cole's idea (1996) finds simultaneousness with Arikewuyo when he portrays pressure as the antagonistic mental and genuine reactions that occur in individuals due to their being not ready to adjust to demands being made on them. Oguntimehin (2006) believes that pressure is the resultant impact of an individual being pushed past the constraint of their normal limit and that even after the reason is taken out; the individual doesn't re-visitation of his/her past state. Symonds (1947) while examining mental confusion in RAF, sees pressure as that which occurs in him. With Hooke's law of versatility, he clarifies it in a more clear structure. This law expresses that if any strain delivered by a given pressure should fall inside the versatile furthest reaches of a material, when the pressure is taken out, the material will re-visitation of his unique condition. This is to state that as actual frameworks have a flexible breaking point so likewise individuals have in-constructed protection from stress to a specific cutoff, however when it becomes excruciating, physiological, mental and sociological issues may emerge.

\subsection{Causes of stress}

What achieves pressure fluctuates from individual to person. To be unpleasant, the occasion should be joined by certain hindrances or hindrance. The boundary might be genuine or envisioned and may appear as dissatisfaction, danger or struggle. Most basic reasons for pressure include: Life occasions or changes, dissatisfaction, minor irritation, persistent uneasiness, danger and general clash. Different elements which could cause pressure, as indicated by Oguntimehin, are: Conflict of interests, absence of occupation fulfillment, framework requests, ridiculous craving for accomplishment, lacking showing assets, delay in advancement, non-accessibility of educating learning material, packing, non-equivalence of compensation with the showing errands, Unwholesome mentality of the general population towards instructors and so forth Nawe (1995) further suggested that each laborer should remain solid by requiring a decent dozing hour in a day; eating great and sufficient eating routine; counseling clinical experts in the event of any pressure side effects; comprising uplifting mentality towards change; dealing with your time appropriately; and defining a practical objective.

\subsection{Effects of job stress in educational system}

Adepoju (2001) distinguished the under recorded as the impacts of word related pressure in instructive framework:

Physical disposition: Stress which continues in individual bodies will in general affect actual wellbeing or aura of the instructor. 
Psychological disposition: Job pressure has sway on mental readiness of people. In this regard, it builds people groups' tension, disappointment, inactivity and animosity just as sadness and self destruction.

Dynamic: To an enormous degree, work pressure blocks successful dynamic in schools since when those burdened with the duty of settling on choices are focused up, there is probability of lingering and shirking of deciding, due to absence of fixation.

Behavioural disposition: Changes in conduct, for example, loss of hunger, expanded liquor utilization, smoking, restlessness, animosity and so on

Execution level: Increased turn-over and truancy, prompting poor or decrease in execution and efficiency. Hackman and oldhmas (1980), highlights the creates of Quality Work Life equivalent to the association among work environment and individual necessities. The work environment that can fulfill agent's necessities is considered to give a positive coordinated effort sway which will incite an extraordinary Quality Work Life. They emphasizd that singular necessities are satisfied when grants from the relationship, for instance, compensation progression, affirmation and improvement meet their supposition. Yesufu (1984) states that condition of being under which an agent works is basic to yield. Office and creation lines that are too hot and inadequately ventilated are debilitating to effort. There should be adequate store of good cautious dress, drinking water, rest rooms, restrooms, and clinical guide workplaces. Both administration and representatives ought to be consistently security cognizant Adamu (1991) characterizes a helpful climate to that which is protected and sound without any dangers and no unnecessary danger. The workplace ought to make a chance to utilize gifts viably to procure new abilities and information for progression. Workers at all levels should have events to build up their abilities through critical thinking and arranging. Likewise, the social atmosphere of the association ought to be liberated from bias and unbending groupings. The work ought not take overabundance time and energy from different parts of life. Asakura and fujigaki (1993), inspected the immediate and the roundabout impact of computerization on laborers' wellbeing and prosperity. Their outcomes were like the investigation of Kaprine (2003) that higher occupation request prompts higher strain workplace henceforth influencing worker's wellbeing and prosperity more. An unstrained workplace guarantees great wellbeing and mental conditions which empower the representatives to perform work and non-business related capacities without restraints, in this manner giving agreeable work life. Heskett, sasser and Schlesinger (1997), characterizes Quality Work Life as the inclination that representatives have towards their positions, associates and to the associations development and productivity. A nice sentiment about their positions implies that the representatives feel upbeat taking care of job which prompts a gainful workplace. This clarification gives a knowledge that the fantastic workplace is considered to give better Quality Work Life. Brenner (2004) bears witness to that the limit of agents inside a relationship to share data all through the system depends upon the condition of their working environment. Anyway, the investigation uncovered that corporate pioneer from various endeavors uncovered that don't totally utilize their genuine work environment. The idea of comfort resultant from the working environment chooses the level of satisfaction and benefit of workers. Workers benefit can't be ideal if the condition of the work environment isn't acceptable. Routray and Satpathy (2007) broadcasted that distinctive pressing factor and observing its effect on our lives require seek after change for instance managing the wellspring of stress positively or possibly changing the library and information science specialists' reaction to it.

\subsection{Theoretical framework}

Work pressure hypothesis: Karasek, (1979) see his discernment on work pressure and dependent on assessment saw the work interest and occupation control as a need to either diminish or build work pressure among bookkeepers. In any case, a powerful hypothesis in exploration about work constantly pressure, the Job 
Demand-Control (JDC) model distinguishes two basic parts of the work inside the work setting: position requests and occupation control (Karasek, 1979). To Karasek (1979), work requests allude to the measure of work executed by a worker (outstanding task at hand). The work control estimation also called the decision extent of the JDC implies a laborer's ability and capacity to have control on their work demands. Decision scope moreover contains two sections: inclination alert and decision power. The rudiments of Karasek's (1979) JDC model is that the solicitations from a work and the control a specialist has over the work team up to make a combination of psychosocial proficient undertakings for the agent and this is dependent on the characteristics of the solicitations from a work and occupation control. Thusly to the JDC model, a responsibility for scope over the solicitations of a work will decrease a laborer's experience of pressing factor and still flood learning, however mental solicitations increase the experience of pressing factor from work and ability to learn.

Quality work life (QWL) Theory: Walton (1975) conceptualized nature of work life to contain eight estimations navigating from adequate and sensible compensation to the headway capacities of the specialist. To Walton (1974) agents' perspective on these estimations at their work place reflects their QWL

These measurements are sufficient and reasonable pay; protected and solid climate; advancement of human limits; development and security; social integrative constitutionalism; the complete life space and social pertinence. As noted, representatives are supposed to encounter a superior nature of work life if the workplace fulfill these eight measurements (Walton, 1975).

\subsection{Methodology}

The study was carried out among practioners in public tertiary institutions captured under the sampling technique. The major instrument used for data collection is questionnaire. The Cronbach method was used to test the reliability of the study, while the hypotheses were tested with a parametric statistical test instrument using analysis of variance (ANOVA).The statistical software SPSS ver.23 was used

\subsection{Data analysis and Results}

Table 1: Demographic Background of Respondents ( $n=41$ )

\begin{tabular}{lcc}
\hline $\begin{array}{l}\text { Variations } \\
\text { Gender }\end{array}$ & Freq. & Percent \\
\hline Male & 13 & 31.7 \\
Female & 28 & 68.3 \\
& & \\
Age & & \\
$30-40$ & 21 & 51.2 \\
$41-50$ & 18 & 44 \\
61 and above & 2 & 4.8 \\
Marital Status & & \\
Married & & \\
Single & 31 & 75.6 \\
& 10 & 24.4 \\
Job Status & & \\
Assistant Librarian- Librarian II & & \\
Librarian I- Senior Librarian & 22 & 53.7 \\
& 12 & 29.3
\end{tabular}


Principal Librarian/ Deputy University Librarian

University Librarian

Ownership

Private

State

Federal
5

2

12.1

4.9

43.9

22

34.1

Table 1 above shows the segment foundation of the respondents. A sum of 28(68.3\%) respondents were females while the excess $13(31.7 \%)$ were guys. $31(75.6 \%)$ were hitched while $10(24.4 \%)$ were single. The status of the respondents are obviously appeared on the table.

Research Hypotheses

\section{Hypothesis One}

$\mathrm{H}_{\mathrm{i}}$ : There is significant effect of job stress among librarians in public tertiary institutions.

\section{ANOVA}

\begin{tabular}{llllll} 
& Sum of Squares & Df & Mean Square & F & Sig. \\
Between Groups & 1.713 & 2 & .857 & 17.891 & .000 \\
Within Groups & 2.598 & 56 & .046 & & \\
Total & 4.322 & 58 & & & \\
\hline
\end{tabular}

Source: Researchers computation SPSS Ver. 23

The computed F-value is 17.891 (Sig. 000), since the p-value is less than the chosen alpha level of .05, we reject the null hypothesis and accept the alternate: 'There is significant effect of job stress among librarians in public tertiary institution'. "Feeling that your job tends to interfere with your family life" and Feeling that you may not be liked and accepted by the people you work with". The Job-related Tension Index was answered on 5point Likert scale format with responses ranging from 'Never' to 'Everyday'.

\section{Hypothesis Two}

$\mathrm{H}_{\mathrm{i}}$ : There is significant effect of job stress on effectiveness of librarian's performance in public tertiary institutions. 
ANOVA

\begin{tabular}{llllll}
\hline & Sum of Squares & Df & Mean Square & F & Sig. \\
Between Groups & 21.118 & 2 & 10.559 & 53.177 & .000 \\
Within Groups & 15.356 & 67 & .166 & & \\
Total & 32.423 & 69 & & & \\
\hline
\end{tabular}

Source: Researchers computation SPSS Ver. 23

The computed F-value is 53.177 (Sig. 000), since the p-value is less than the chosen alpha level of .05, we reject the null hypothesis and accept the alternate that: 'There is significant effect of job stress on effectiveness of librarian's performance in public tertiary institution

\section{Hypothesis Three}

$\mathrm{H}_{\mathrm{i}}$ : Job stress has significant effect on librarians in public tertiary institutions.

ANOVA

\begin{tabular}{llllll} 
& Sum of Squares & Df & Mean Square & F & Sig. \\
Between Groups & 19.254 & 2 & 9.627 & 99.691 & .000 \\
Within Groups & 5.679 & 67 & .100 & & \\
Total & 24.933 & 69 & & & \\
\hline
\end{tabular}

\section{Source: SPSS Ver. 23}

The computed F-value is 99.691 (Sig. 000), since the p-value is less than the chosen alpha level of .05, we reject the null hypothesis and accept the alternate that 'Job stress has significant effect on librarians in public tertiary institution'

\subsection{Discussion of Findings}

These discoveries recommend that the nature of work life of the examined test is in danger within the sight of gigantic work. I thusly suggest that tested associations can take part in activities or exercises that will decrease work pressure which will over the long haul help the nature of work life. These exercises may incorporate the utilization of the Job Demand Control model as a pressure decrease measure and this can be accomplished by 
giving representatives the required scope to execute their works. Additionally, bosses may improve the determination and position cycle to get the perfect individuals at the perfect spot. Consequently ensuring that people are accommodated their workplace. Nature of work life is an exceptionally wide idea with a wide range of insights about it and, in this way, hard to characterize. Numerous creators, clinicians and the executive's specialists concur that it is hard to give an away from of the term nature of work life, other than that it has to do with the prosperity of representatives. All theories concur that nature of work life isn't simply work fulfilment, which is just one among its numerous viewpoints. All acknowledge that various individuals will have alternate points of view on what makes for high calibre of work life. The effect of work life on the individual is the result of many collaborating factors, of which the significance of each can vary from gathering to gathering and occasionally.

\subsection{Summary of findings}

Regarding hypothetical significance, discoveries from this examination makes a few commitments to existing collection of information and even more explicitly to the arising and creating writing of mental capital just as sure brain research. Likewise, aftereffects of this examination show that, versatility, a segment of work pressure, can alleviate the negative results that work pressure has on representative nature of work life. Accordingly, building up the regard level of the administrators especially versatility can give representatives the required influence to withstand the negative outcomes of work pressure that the present universe of work welcomes on the worker just as acquire gigantic hierarchical effect terms of profitability and effectiveness.

\subsection{Conclusion}

Discoveries from this examination propose that a negative relationship exist between work pressure and quality work life. Nonetheless, flexibility (a segment of pressure) was found to incompletely intervene the work pressure quality work life relationship. Finally, the outcomes indicated that work pressure somewhat interceded the mental capital-nature of work life relationship. The above investigation is in accordance with Schneider (1991) who saw in an examination that absence of adequate number of staff to deal with remaining burden had impacts on the strength of laborers. The individuals who revealed elevated level of pressure apparent their work to be requesting and less fulfilling. This also maintained Akinboye, Akinboye and Adeyemo ((2002) about the spot of significant leftover job needing to be done in delivering pressure. The work uncovers that overseers devise different strategies for settling pressure. They lessen pressure through work/administration withdrawal and social cooperations in workplace. Associations and representatives in the public tertiary establishments are persistently going to be stood up to with quick mechanical changes, expanded rivalry, consistent consumer loyalty, work broadening, position updating, authoritative rebuilding, cutting back just as right estimating and these issues will ceaselessly put tremendous weight on representatives to continually convey and meet their objectives. It is accordingly basic that associations put in much exertion to build up the flexibility just as personal satisfaction style level of representatives since it has been appeared in this investigation to alleviate the contrary impacts of work pressure just as assurance better quality life separately.

\subsection{Recommendations for further study}

The effects and impact of stress on librarians and their output cannot be overemphasized. It results in chronic sicknesses and loss of man hour. It is therefore necessary to reduce pressure to the barest level in the library working environment. Creating healthy working environment is paramount in this regard. The provision of adequate facilities is also important since it helps librarians to perform maximally. In view of the importance and interest this study has generated, 1 recommend that this study be carried out in public and private tertiary institutions across the country. It will allow for comparison between public and private tertiary institutions. 


\section{References}

Adamu S. O. (1991). Productivity data and nation building. London, Croner

Asakura, R. \& Fujigaki, Y (1993). The impact of computer technology on job characteristics and worker health, Elsevier pp 982-987

Bunge, C. (1987). Stress in the Library. Library Journal vol. 112(5), pp47-51.

Brenner P. (2004). Workers physical surrounding. Impact Bottom Line Accounting. : Smart Pros.Com

Colligan, T. W., \& Higgins, E. M. (2006). Workplace stress etiology and consequences. Journal of Workplace Behavioral Health, 21(2), 89-97.

Gazzaniga, M. S. \& Heatherton, T. F. (2003). Psychological Science: Mind, Brain, and Behaviour. New York: W. W. Norton \& Company.

Goodale, J.G., Hall D.T., Burke R. J, \& Joyner R.C (1975). The quality of working life problems prospects and the state of art, New York: Free Press

Hackman J. R.\& Oldham G. R. (1980) Work Redesign. Addison- Wesley

Hart, A. (2007). Thrilled to death. Nashville, TN: Thomas Nelson.

Henry, O., \& Evans, A. J. (2008). Occupational stress in organizations. Journal of Management Research, 8(3), 123-135.

Heskett, J. L, Sasser W. E \& Schlesinger (1997).The service profit chain. New York: Free Press.

Ilo, P.I. (2008). Resources sharing in Academic Libraries in Nigeria: a Digital Imperative. Global Review of Library and Information Science, vol.4, pp.1-13.

Karasek, R. A. (1979). Job demands, job decision latitude and mental strain: implications for job design. Administrative Science Quarterly, 24, 285-308.

Lau, T. U., Wong, Chan K F and Law M (2001) Information technology and the workenvironment, human systems management pp 267-280

Lehnert, P. (2002). Stress management. Baylor Health Care System. In www.Baylorhealth.edu

Lowe, G. S (2000). The quality of work: A people centered agenda. Canada: oxford university press

Mirvis, P.H. and Lawler, E.E. (1984) Accounting for the Quality of Work Life. Journal of Occupational Behaviour. 5. 197-212

Nawe, J.(1995). Work-related stress among the library and information work force. Library Review.vol.44 (6): pp. $30-37$

Routray, B. and Satpathy, S. (2007). Stress management of library and information science professionals in digital environment. LIS e-prints in Library and Information Science.www.eprints.rclis.org .

Serey, T. T. (2006) Chosing a robust quality of work life. Business forum 27(2) pp7-10

Walton, R. E. (1974). QWL indicators: Prospects and problems. In A. H. Portigal (Eds.). Measuring the quality of working life. A symposium on Social Indicators of Working Life. Ottawa, March, 19-20.

Walton, R. E. (1975). Criteria for quality of working life. In L. E. Davis, \& A. B. Cherns (Eds.), The Quality of Working Life, 1(2), 93-97.

Yesufu, T. M. (1984). The dynamics of industrial relations. Ibadan University Press 